\title{
Os conflitos na mineração e a Justiça \\ Diamantina, Minas Gerais, décadas de 1850-1880*
}

\section{The conflicts in mining and the Justice \\ Diamantina, Minas Gerais, decades of 1850-1880}

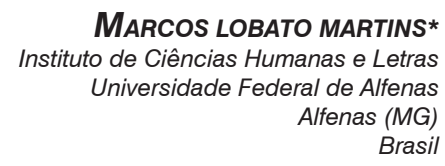

RESUMO Este artigo analisa os conflitos surgidos nos serviços de lavra entre agentes da mineração de diamantes na região de Diamantina, Minas Gerais, nas décadas de 1850-1880. O objetivo é investigar o papel desempenhado pela Justiça na solução desses conflitos. Mostra-se que os mineradores de diamante não hesitaram em recorrer à Justiça quando se viram envolvidos em demandas sobre a posse e a exploração de jazidas ou sobre a divisão do produto da lavra. As fontes utilizadas foram documentos da Administração Geral dos Terrenos Diamantinos e ações arbitrais existentes nos cartórios de Diamantina.

Palavras-chave ações de arbitragem, conflitos na mineração, Diamantina, século XIX

ABSTRACT This paper analyzes the conflicts that arose in the mining works between diamond's miners in the region of Diamantina, Minas Gerais, in the

* Artigo recebido em: 02/02/2013. Aceito em: 16/08/2013.

**Contato: lobatohistoria@hotmail.com. 
decades of $1850-1880$. The aim is investigate the role played by Justice in the solution of these conflicts. It is demonstrates that the diamond's miners did not hesitate in to appeal for Justice when were involved in questions about propriety and exploration of mines or about the division of the mining product. The sources used were documents of the General Administration of Diamond Lands and actions of arbitrage existent in Diamantina's registries.

Keywords actions of arbitrage, conflicts in mining, Diamantina, Nineteenth century

Em 25 de agosto de 1927, o minerador Franklin de Carvalho comprou de Dona Luiza Maria do Rosário Fernandes parte das terras da fazenda Câmara, contendo moinho, casas e lotes diamantinos pela quantia de dez contos de réis. Os terrenos, situados na localidade de Sopa, abrigavam 14 lotes minerais, uns na Sopa e outros nos Caldeirões. ${ }^{1}$ Nessa área, Franklin Carvalho e seus filhos Antônio e Cristóvão fizeram serviços de mineração, lado a lado com outro minerador, Vidal Pio Fernandes. Porém, no ano de 1931, surgiu entre eles uma desavença por causa de um regato de que ambos se utilizavam para minerar. A rixa entre Carvalho e Fernandes cresceu, terminando em tiroteio no qual morreram Franklin de Carvalho e seu filho Antônio e um garimpeiro camarada de Vidal Pio Fernandes. Segundo notícia do jornal diamantinense Pão de Santo Antônio, a cidade ficou consternada. Ao velório e ao enterro de Franklin de Carvalho e seu filho compareceu enorme multidão, indignada com a violência que grassava nos garimpos. ${ }^{2}$ A multidão exigiu rápida resposta das autoridades - já estaria na hora de acabar com as brigas e as mortes nas lavras, porque Diamantina era uma cidade civilizada.

Esta perspectiva que associa irremediavelmente desordem e violência com garimpo permaneceu dominante século XX adentro. Nos anos 1950, por exemplo, a poetisa Cecília Meireles, no conhecido Romanceiro da Inconfidência, insistiu na imagem triste e negativa das minas de ouro e diamantes, na qual "grossas vagas tenebrosas/ nascem no humano destino!/ Uns, ali, nas rudes catas,/ a apodrecerem nos rios,/ - e outros, ao longe, com os lucros/ dessas minas de martírio". ${ }^{3}$ Para a poetisa, enquanto "mil bateias vão rodando/ sobre córregos escuros", o ouro e o diamante brotavam claros e tudo turvavam - "honra, amor e pensamento". Os negros definhavam nas

\footnotetext{
Biblioteca Antônio Torres (BAT). Livro de Notas n.44, Cartório do $1^{\circ}$ Ofício, 1927, maço 498, fl.20-21v.

BAT. Pão de Santo Antônio, Diamantina, Ano XXVI, n.7, 01/11/1931, maço 157, gaveta 04

MEIRELES, Cecília. Romanceiro da Inconfidência. 9 ed. São Paulo: Global, 2012, p.63.
} 
águas, as famílias disputavam privilégios, o fisco extorquia as gentes, as autoridades cometiam desvarios, prendendo culpados e justos. Por isso, nas terras da antiga Demarcação Diamantina, "já ninguém dorme tranquilo,/ que a noite é um mundo de sustos". ${ }^{4}$ Do senso comum e da literatura regional, essa poderosa e ancestral imagem, a das zonas de mineração como um mundo de sustos, invadiu as páginas dos memorialistas e até mesmo as obras de eminentes historiadores.

O objetivo deste artigo é identificar e analisar indícios que contribuam para colocar em xeque o lugar-comum historiográfico anteriormente citado. Noutras palavras, trata-se de compreender a complexa natureza dos conflitos que, nos Oitocentos, enredaram mineradores e autoridades no território da antiga Demarcação Diamantina. Interessam aqui as disputas nas quais os serviços de lavra ocuparam o centro dos acontecimentos, e, na dinâmica dessas querelas, investigar o papel desempenhado pelas instâncias oficiais, especialmente a Administração Geral dos Terrenos Diamantinos e a Justiça local. O que se pretende mostrar é que o recurso à Justiça, tanto por parte dos grandes mineradores como por garimpeiros e faiscadores, fazia parte do repertório de ações dos sujeitos que viviam da extração de diamantes. Eles não hesitaram em procurar a Justiça quando se viram envolvidos em "demandas" sobre a posse e a exploração de lotes de terras minerais. Recurso que, em muitos casos, evitou - ou pelo menos adiou - o emprego da violência nas áreas de mineração do Nordeste de Minas Gerais.

O recorte cronológico abrange o período dos primeiros anos de efetivo funcionamento da Administração Geral dos Terrenos Diamantinos. Como se sabe, a Real Extração - regime de monopólio régio, instituído no tempo do governo pombalino - foi extinta pelo decreto de 24 de setembro de 1845. Criou-se, então, nova repartição composta por um inspetor geral, um procurador fiscal, um secretário e um engenheiro prático, sediada na cidade de Diamantina e com delegacias no Serro, em Grão-Mogol, São Romão, Conceição do Mato Dentro, Bagagem e Uberaba. Subordinada à Tesouraria da Fazenda da Província, a Administração Geral dos Terrenos Diamantinos era responsável pela administração e fiscalização dos lotes arrendados para extração de diamantes. A repartição instituía os contratos de arrendamento dos terrenos minerais levados a hasta pública. ${ }^{5}$ No entanto, como surgiram várias dificuldades na aplicação do referido decreto, notadamente no caso dos indivíduos que já exploravam os aluviões diamantinos e não possuíam recursos para arrendá-los, a atuação da Administração Geral ficou praticamente bloqueada até 1852. Nesse ano, foram aprovados adendos

MEIRELES, Cecília. Romanceiro da Inconfidência, p.28.

5 O prazo de duração dos contratos era de 4 anos, podendo ser renovados indefinidamente caso houvesse interesse do arrendatário. 
ao decreto que legitimaram as ocupações antigas. Dessa forma, no ano seguinte a repartição entrou efetivamente em atuação. ${ }^{6}$

As fontes empregadas neste artigo foram processos de arbitramento e ações arbitrais existentes nos Cartórios do $1^{\circ}, 2^{\circ}$ e $3^{\circ}$ Ofícios da Comarca de Diamantina, hoje sob a guarda da Biblioteca Antônio Torres (BAT). Também foram utilizados documentos da Administração Geral dos Terrenos Diamantinos, pertencentes ao "Fundo dos Terrenos Diamantinos" (TD) do Arquivo Público Mineiro (APM). Lançou-se mão, ainda, dos registros das cadernetas que compõem o Acervo José Teixeira Neves, nos quais há informações a respeito de conflitos envolvendo mineradores e autoridades na segunda metade do século XIX. ${ }^{7}$

\section{Tensões, tumultos e conflitos nas áreas de lavra diamantina}

Os terrenos ricos em depósitos de diamante atraíram, desde os tempos coloniais, multidões de homens livres e escravos que, coletiva ou individualmente, escavaram os cascalhos de aluviões e grupiaras em busca de pedras preciosas e de ouro. Tais ajuntamentos humanos, dominados por movimento nervoso e submetidos à mais severa vigilância de donos de lavras e autoridades fiscais, produziram muita riqueza, como também muitos distúrbios que ameaçaram continuamente a ordem pública no interior da antiga Demarcação.

A historiografia capturou bem esta dimensão conflituosa das regiões mineradoras. A começar pelo texto clássico de Joaquim Felício dos Santos, Memórias do Distrito Diamantino, escrito na década de 1860, no qual o tribuno diamantinense enfatizou a opressão fiscal e a violência das autoridades que se abateram sobre as populações da antiga Demarcação no século XVIII. ${ }^{8}$ Para Felício dos Santos, todos os moradores do Tijuco, indistintamente, penaram com os abusos, as injustiças e as violências perpetrados por ouvidores, contratadores, intendentes. O autor denunciou as perseguições movidas contra os garimpeiros, transformando um deles, o Capitão Isidoro, aprisionado, torturado e morto pelo Intendente Câmara, em mártir. Conforme Felício dos Santos, o Distrito Diamantino tornou-se uma área diferenciada na colônia, um "estado dentro do estado", em razão dos regulamentos draconianos e do peso opressivo do aparato governamental local, direta e exclusivamente vinculado a Lisboa. Esta imagem do Distrito

6 SANTOS, Joaquim Felício dos. Memórias do Distrito Diamantino. Belo Horizonte: Itatiaia, 1976.

7 O diamantinense José Teixeira Neves foi funcionário do Arquivo Nacional no Rio de Janeiro que compilou, ao longo de sua vida, as mais variadas informações que encontrava sobre sua terra natal, registrando-as em cadernetas. Os jornais e a tradição local constituíram as fontes privilegiadas dos registros de José Neves. As cadernetas foram doadas pela família à Biblioteca Antônio Torres.

8 SANTOS, Joaquim Felício dos. Memórias do Distrito Diamantino. 
Diamantino permaneceu viva até a década de 1990, quando veio a público o trabalho de Júnia Ferreira Furtado.

Em O Livro da Capa Verde: o Regimento Diamantino de 1771 e a vida no Distrito Diamantino no período da Real Extração, a pesquisadora contestou a ideia da excepcionalidade da antiga Demarcação. ${ }^{9}$ Furtado mostrou que a área possuíra padrões demográficos e de vida social similares aos de outros pontos da colônia. Mostrou também que as autoridades do Distrito Diamantino, no período da Real Extração, subordinavam-se ao controle e à vigilância dos governos da Capitania de Minas Gerais, contestando a tese do "estado dentro do estado". Júnia Furtado insistiu na situação de descontrole em que vivia a Demarcação, sinalizada exatamente pela reiteração de normas draconianas pelos administradores regionais, cuja eficácia era baixa. Ela também enfatizou o peso das arbitrariedades e violências que recaía sobre as camadas pobres da sociedade, enquanto as pessoas abastadas gozavam de salvo-condutos e privilégios que lhes protegiam do despotismo das autoridades.

Nesta linha que ressalta o fracasso da administração portuguesa em impor eficazmente a ordem pública nas Minas Gerais, do que resultariam a permanente desordem e os altos níveis de violência presentes na vida cotidiana dos habitantes da Capitania, situa-se ainda a pesquisa de Ivana Denise Parrela, relativa ao descontrole da região de garimpo de diamantes na Serra de Itacambiruçu. ${ }^{10}$ Esta área, ao norte da antiga Demarcação Diamantina, ao redor de Grão-Mogol, foi palco de muitos assassinatos e assaltos, cometidos por bandos armados (como o bando de João Costa e o dos Virasaias), e da ação de potentados e seus comparsas mulatos, de contrabandistas e autoridades e soldados corruptos. Ali, os conflitos entre tropas da Capitania e garimpeiros foram intensos, produzindo muitas mortes. Embora houvesse combates de grandes proporções, o conflito se caracterizou pela estratégia de guerrilha, com pequenos e constantes confrontos, queima de ranchos dos dois lados e sabotagem das áreas de exploração. As autoridades coloniais, sob o comando do Governador de Capitania Dom Rodrigo de Menezes, desencadearam repressão brutal sobre os faiscadores e garimpeiros que contestavam a presença oficial nos novos "descobertos".

No século XIX, a Administração Geral dos Terrenos Diamantinos mostrou-se atenta aos numerosos fatores que poderiam abalar a precária ordem e a frágil paz nas áreas de lavra. Veja-se, a respeito, o ofício enca-

9 FURTADO, Júnia Ferreira. O livro da capa verde: o Regimento Diamantino de 1771 e a vida no Distrito Diamantino no período da Real Extração. São Paulo: Annablume, 1996.

10 PARRELA, Ivana Denise. O teatro das desordens: garimpo, contrabando e violência no sertão diamantino, 17681800. São Paulo: Annablume, 2009. 
minhado pelo Inspetor-Geral ao Presidente da Província de Minas Gerais, Conselheiro Vicente Pires da Mota:

$1^{\circ}$ de março de 1861. Aparecendo no $1^{\circ}$ Distrito Diamantino, destinado a faiscadores, uma pequena pinta dentro do Arraial do Curralinho alguns habitantes deste Distrito requereram cartas de faiscadores, e principiaram a lavrar de comunhão com os donos do solo, mas a inveja e a ambição de ter logo veio perturbar o sossego público a ponto de se recear uma sublevação como se espalhou, mas tomando-se imediatamente cautelosas e prudentes medidas ao meu ver, pude conseguir restabelecer a ordem e continuarem-se os trabalhos anteriormente havidos, mas dando-se estes exemplos quase sempre em ocasiões de maior ou menor descoberto, torna-se de meu dever levar este ocorrido ao conhecimento de $V$. Exc. e novamente importunar-lhe pela abreviada remessa da força [policial] que provavelmente espero segundo me foi comunicado de ordem de V. Exc. pelo $1 \mathrm{~m}^{\circ}$ Sr. Secretário em data de 12 do mês pp. ${ }^{11}$

O ofício do Inspetor-Geral da Administração dos Terrenos Diamantinos, contendo indisfarçável autoelogio de sua diligente autoridade, aponta para a percepção de que, nas lavras, invariavelmente imperam a ambição e a inveja, pululam desordens que podem levar a graves distúrbios. Os grandes descobertos teriam o condão de despertar o desejo voraz do rápido enriquecimento, liberando instintos perversos contidos somente pela ação civilizadora da autoridade e pelo poder de polícia do Estado.

$\mathrm{Na}$ verdade, o episódio citado pelo Inspetor-Geral estava vinculado aos conflitos que se seguiram ao descoberto de diamantes no centro do povoado de Curralinho. De acordo com o relato de José Teixeira Neves, formou-se uma sociedade para explorar a área, a qual principiou os serviços lavrando os quintais e ruas e demolindo casas. O povo invadiu o serviço, havendo resistência por parte dos posseiros. A intervenção do Juiz Municipal evitou conflitos iminentes, e houve embargo do serviço até a chegada de instruções da Tesouraria da Fazenda. ${ }^{12}$

Para a autoridade reguladora das lavras, a hora de agir deveria ser a do momento mesmo da descoberta mineral. Não haveria tempo a perder, do contrário a atmosfera de desordem poder-se-ia tornar pesada demais e, então, praticamente incontrolável ficaria a área mineral. Ainda assim, a "boa ordem" nas zonas de mineração exigia vigilância contínua. Afinal, haveria que se botar freio aos invasores de lavras, como se pode ver no ofício enviado à Delegacia do Serro, no qual foram dadas instruções para combater a invasão no lote contratado por Dona Carolina Gabriela da Fonseca:

O Inspetor-Geral dos Terrenos Diamantinos da Província de Minas Gerais faz saber ao Sr. Delegado dos mesmos no município do Serro (...) que cumpre

11 APM. Livro de Ofícios expedidos pela Administração Diamantina (1855-1886), fl.28. TD-04.

12 BAT. Acervo José Teixeira Neves. Caixa 3, Livro 1, fl.XXXVIII. 
a essa Delegacia mandar intimar os invasores a que se retirem tomando ao mesmo tempo uma relação dos que ali forem encontrados trabalhando a fim de serem multados e executados; e no caso de resistência ou reincidência deve a arrendatária requerer à autoridade judiciária instaurar o respectivo processo. É esta a praxe seguida em casos idênticos, a qual essa Delegacia deve seguir. Secretaria da Administração, 12 de março de $1886 .{ }^{13}$

Igualmente contínua deveria ser a perseguição à mineração ilegal, entendida como a realização de catas em locais não demarcados ou sem a cobertura de contratos de arrendamento firmados na Administração Diamantina. Esse era o caso, por exemplo, da faiscação que se fazia na Mata dos Crioulos, em princípios do ano de 1868, que motivou a ordem para o Delegado de Polícia de Diamantina, Tenente João Teodoro Fernandes:

31 de março de 1868. Denunciando perante V. S. o Capitão Antônio Mendes de Magalhães que no lugar denominado Mata dos Crioulos acha-se um grupo de pessoas minerando, sem título legítimo, os terrenos diamantinos situados em aquele lugar, a bem do serviço público e para que sejam respeitados os direitos da Fazenda Nacional requisito de V. S. os praças que julgar necessários a fim de, auxiliados pelo Porteiro desta repartição, irem ao lugar vedar este ato criminoso. ${ }^{14}$

Por que o Capitão Antônio Mendes de Magalhães, rico fazendeiro diamantinense, deu-se ao trabalho de denunciar faiscadores que mineravam em suas terras? Não se trata somente de zelo cidadão. Mais que o cumprimento da Lei, ao Capitão Magalhães talvez interessasse o dinheiro que era costume o minerador pagar ao dono do solo onde se situava a lavra. ${ }^{15}$ Costume que incidia sobre os garimpeiros e grandes mineradores, que podia ser exigido com maior força daqueles que estavam regularmente inscritos nos livros de contratos da Repartição Diamantina. ${ }^{16}$ Arranjo típico que revela existirem oposições entre mineradores e donos de terras, cuja solução passava pela construção de compromissos à margem da Lei, embora frequentemente reconhecidos pelas esferas oficiais.

13 APM. Livro de Ofícios expedidos pela Administração Diamantina (1855-1886), fl.52. TD-04.

14 APM. Livro de Ofícios expedidos pela Administração Diamantina (1855-1886), fl.43. TD-04.

15 Em Diamantina, a percentagem requerida pelo proprietário do solo ficava entre 5 e 10\% da "apuração". A respeito das tradicionais divisões do produto das lavras entre donos dos serviços, proprietários de terras e trabalhadores da mineração, ver MARTINS, Marcos Lobato. Identidades sociais e ação coletiva: o caso dos garimpeiros da microrregião de Diamantina. Belo Horizonte: Universidade Federal de Minas Gerais, 1997 (História, Dissertação de mestrado).

16 Conforme o regime dominial instituído pela Constituição de 1824, o proprietário fundiário do terreno onde havia jazidas tinha o direito à preferência para exploração do subsolo, bem como direito a indenização por danos eventualmente causados pelos serviços de lavra conduzidos por terceiros. As interpretações controversas da Constituição de 1824 geraram indefinições sobre a separação da propriedade do solo e do direito de minerar. Os grandes mineradores tenderam a recusar o pagamento de percentual do resultado bruto do serviço de lavra aos donos da terra. Ver CATHARINO, José Martins. Garimpo, garimpeiro, garimpagem. Rio de Janeiro/Salvador: Philobiblion/Fundação Econômica Miguel Calmon, 1986; CALÓGERAS, João Pandiá. As minas do Brasil e sua legislação. Rio de Janeiro: Imprensa Nacional, 1904; 3 v; VASCONCELOS, José Matos de. Direito Administrativo. Rio de Janeiro: Imprensa Nacional, 1936. 
Os faiscadores concentraram as preocupações das autoridades relativas à manutenção da ordem pública. Em 1861, avultado número deles foi reprimido nas proximidades de Diamantina quando tentava minerar em uma das vertentes do rio das Pedras. As tropas da Guarda Nacional dispersaram os faiscadores, debaixo da alegação de que eles prejudicavam o manancial que abastecia de água o rego público da cidade. ${ }^{17}$ Anos depois, em 1873, faiscadores e garimpeiros invadiram o Pau de Fruta. Lá chegaram a trabalhar de 5 a 6 mil faiscadores, que improvisaram, em uma semana, uma povoação, "espécie de república bem organizada". As autoridades intervieram para dispersar o ajuntamento. Duas companhias de soldados da Polícia, comandadas pelo Capitão Felipe Coelho dos Santos, foram necessárias para manter a ordem durante a desocupação. ${ }^{18} \mathrm{~A}$ simples presença de faiscadores parecia pressagiar a ocorrência de distúrbios graves. Nesse sentido, as autoridades da Administração Geral dos Terrenos Diamantinos conservaram as mesmas opiniões dos antigos dirigentes coloniais, para quem os faiscadores eram "vadios", facinorosos, "desclassificados sociais" perigosos ao sossego dos povos. ${ }^{19}$ É o que se lê no ofício do Inspetor-Geral José João Ferreira de Souza Coutinho, enviado à Tesouraria da Fazenda em 8 de fevereiro de 1861, a respeito de medidas para melhorar a mineração:

O estado geral dos terrenos diamantinos ao que suponho não é o mais próspero, porque são eles explorados em grande parte por especuladores sem título, homens audazes e aventureiros, que não se sujeitam a ação das autoridades, as quais não têm nem a força e nem o prestígio de podê-los conter nos limites de sua obediência, para fazer executar a Lei em lugares longínquos e despovoados onde podem eles facilmente ocultar os seus trabalhos por falta de força suficiente para a guarda e fiscalização dos mesmos terrenos. ${ }^{20}$

Outra fonte potencial de desordem nas áreas de lavra residia na dificuldade de controlar os numerosos negócios de lotes diamantinos, muitos dos quais mudavam de mão facilmente, e por diversas vezes. Uma vez arrematados, os lotes transformavam-se em objetos de transações formais e informais. Alguns exemplos são suficientes para dar ideia do volume desse mercado de direitos minerários. Em 18 de fevereiro de 1857, Dona Maria Antônia de Amorim e seus filhos e genros cederam e venderam a José Pereira Guimarães Júnior e seus irmãos Antônio, Domingos e Joaquim Pereira Guimarães, a quinta parte da lavra denominada "Barro" que arrendou nas cabeceiras do córrego de São João, pela quantia de quatro contos de réis. Os vendedores se obrigaram cada um por si a continuar no arrendamento

17 BAT. Acervo José Teixeira Neves. Caixa 3, Livro 1, fl.XXXVIII.

18 BAT. Acervo José Teixeira Neves. Caixa 3, Livro 1, fl.XXXVI.

19 MELLO E SOUZA, Laura de. Desclassificados do ouro: a pobreza mineira no século XVIII. 2 ed. Rio de Janeiro: Graal, 1986.

20 APM. Livro de Ofícios expedidos pela Administração Diamantina (1855-1886), fls.21-22v. TD-04. 
da lavra. ${ }^{21}$ Em 26 de fevereiro de 1874, Cassiano Feliz Ferreira vendeu a João da Matta Machado uma casa coberta de capim, com chácara e água, situada no lugar denominado Baú, no subúrbio de Diamantina, bem como o direito que tinha em dois lotes de terrenos diamantinos no córrego do Baú, tudo pela quantia de quinhentos mil réis. Um dos lotes media seis mil braças quadradas; o outro, oito mil braças quadradas. ${ }^{22}$ No mesmo ano, em 31 de outubro, Venâncio Ribeiro Mourão, proprietário de um lote de terrenos diamantinos de seis mil braças quadradas no ribeirão do Inferno, lugar denominado Dacamão, vendeu pela quantia de dois contos de réis a Denis Moreira dos Santos um lance de serviço de mineração. Pelo acordo, ao vendedor e seus filhos ficava o direito de explorar a lavra vendida com vinte praças vivas, não sujeitas a condição alguma. Assim, Venâncio Mourão e Denis dos Santos passaram a formar uma sociedade de mineração. ${ }^{23} \mathrm{~A}$ Administração Geral dos Terrenos Diamantinos desdobrava-se diante da necessidade de conhecer os meandros desses negócios, especialmente por causa dos impactos fiscais deles decorrentes. Afinal, ela deveria saber exatamente quem eram os titulares dos direitos para deles cobrar os impostos e taxas devidos à Fazenda Pública.

A tranquilidade nas zonas de mineração dependia ainda da manutenção em boa ordem dos trabalhos nos serviços de lavra. Era fundamental prevenir problemas decorrentes de erros ou interpretações incorretas das demarcações dos lotes minerais, bem como estabelecer precisamente a titularidade dos direitos minerários. Os oficiais da Administração Geral dos Terrenos Diamantinos deveriam fiscalizar regularmente os ribeiros diamantinos, percorrer as catas e dirimir eventuais desentendimentos entre os mineradores, especialmente aqueles que exploravam lances de serviço vizinhos. As querelas sobre limites das catas, uso da água, construção de canais, quantidade de "praças vivas" empregadas, divisão do produto e das despejas das catas, tudo isso poderia ensejar o nascimento de rixas entre os mineradores. E as rixas facilmente resvalavam para o campo da violência, provocando a paralisação dos serviços e sobressaltando as gentes.

É justamente dos conflitos surgidos no âmbito da garimpagem que se tratará adiante.

\section{As reformas da Justiça e as ações arbitrais: breve parêntesis}

É bem conhecido o fato de que, nas primeiras décadas posteriores à Independência, o Brasil viveu época de grande experimentação no que se refere às formas e aos dispositivos da Justiça. Muitas mudanças ocorreram

21 BAT. Escritura de cessão e venda. Livro de Notas n.8, Cartório do $1^{\circ}$ Ofício, maço 44, fls.49v-51.

22 BAT. Escritura de venda. Livro de Notas n.6, Cartório do $3^{\circ}$ Ofício, maço 162, fls.6-8.

23 BAT. Escritura de venda. Livro de Notas n.7, Cartório do $3^{\circ}$ Ofício, maço 162, fls.50v-52. 
visando dotar o Império de leis adequadas à Constituição outorgada em 1824 e que favorecessem a marcha civilizatória do país. Assim, adotaram-se medidas disciplinadoras dos aspectos processuais da Justiça e aprovaramse códigos definidores de nova estrutura jurídica. Entre eles, o Código Criminal (1830) e o Código do Processo Criminal (1832). Nos debates sobre a reforma da Justiça, mobilizadora de disputas em torno do processo de construção nacional, afloraram dilemas entre público e privado, centralização e descentralização, liberalismo e conservadorismo.

De início, o experimento liberal deu o tom das mudanças judiciárias. A lei de 15 de outubro de 1827 criou o juiz de paz eletivo nas freguesias. Com amplas atribuições, o juiz de paz promovia justiça conciliatória e julgamento de causas de pequeno valor e/ou pena, impunha o bem viver e o cumprimento das posturas municipais, conduzia as eleições, mantinha a ordem pública e emprego da força pública. ${ }^{24}$ Por isso, o posto de juiz de paz tornou-se foco das disputas entre facções políticas nos anos 1830 e alvo de críticas severas dos magistrados do Império. O juiz de paz representou ponto a favor das concepções liberais a respeito da descentralização do poder e da ordem jurídica. Na mesma direção seguiu o Código de Processo Criminal, dando novo desenho para a Justiça brasileira. Por ele, em cada comarca surgia a figura do juiz de direito (máximo de três, nomeados pelo Imperador), bacharel formado em lei, um chefe de polícia (nas cidades mais populosas, um dos juízes). Nos termos, haveria um juiz municipal e um promotor (nomeados pela Corte e presidente de província, por indicação de lista tríplice das câmaras municipais, preferencialmente graduados em Direito), um escrivão de execuções, oficiais de justiça e um conselho de jurados (alistamento). Nos distritos, o Código de Processo Criminal manteve a figura do juiz de paz eleito, escrivão, oficiais de justiça e inspetores de quarteirão (todos nomeados pelas câmaras). Reforçava-se, assim, a descentralização da estrutura judiciária e policial. A expansão do sistema jurídico ocorria, então, associada à ampliação da participação da sociedade local na organização jurídica. As dificuldades de implantação das propostas do Código de 1832, os comprometimentos eleitorais dos cargos judiciais nos municípios e o controle dos grupos locais das indicações e nomeações fizeram crescer as críticas dos contemporâneos ao exercício eficaz e isento da Justiça.

A partir do movimento do Regresso, que culminaria, nos anos 1840, com a vitória do projeto saquarema, as reformas do sistema judiciário brasileiro foram dominadas por duas ideias centrais. A primeira era a de retirar definitivamente a Justiça do controle da aristocracia local, que a ad-

24 A referência clássica sobre a figura do juiz de paz é a obra de FLORY, Thomas. El Juez de Paz y el Jurado em el Brasil Imperial, 1808-1871: control social y estabilidade política em el nuevo estado. México: Fondo de Cultura Económica, 1986. 
ministrava conforme seus interesses particulares, promovendo ao máximo a centralização da distribuição de cargos e da tomada de decisões, para que a Justiça servisse ao projeto político da Corte. A segunda era conferir à Justiça maior eficiência e racionalização. Em 1841, com a promulgação da lei de 3 de dezembro, selou-se a vitória da centralização da máquina judiciária. ${ }^{25}$ Esta lei esvaziou a figura do juiz de paz, transferindo a maior parte de seus poderes para delegados e subdelegados de polícia, subordinados ao chefe de polícia provincial diretamente ligado ao Ministério da Justiça. Os juízes passaram a ser nomeados pelo Imperador e, na prática, todos os cargos e indicações ficaram nas mãos do ministro da Justiça. Por conseguinte, a estruturação do quadro jurídico voltou-se para a formação de uma burocracia de Estado, remunerada e controlada pelo poder central, com o que se avançava na monopolização e controle da máquina administrativa.

No plano da legislação, os diversos códigos promulgados na primeira metade do século XIX enfrentaram os problemas da morosidade da justiça e da impunidade, resultantes da legislação caótica do período colonial, sua profusão de leis, alvarás e decretos, que possibilitava esticar as demandas judiciárias por meio do recurso a filigranas processuais. ${ }^{26}$ Houve esforço contínuo no sentido de positivação das leis, importante movimento em prol da codificação do direito no Império, valorizando a interpretação com base no texto da lei e a formação de jurisprudência no Brasil. A preocupação com a "unidade de jurisprudência", tão bem expressa no relatório anual de 1854 do ministro da Justiça Nabuco de Araújo, constituiu elemento destacado do ambiente de operação da Justiça no período, pressionando advogados e magistrados e estabelecendo os limites cada vez mais estreitos para as estratégias e os procedimentos jurídicos. ${ }^{27}$ Ao mesmo tempo, as autoridades insistiram na necessidade de preenchimento dos cargos do Judiciário por pessoas instruídas, profissionais, bacharéis em Direito.

Observa-se também modificação no padrão de argumentação e julgamento dos processos. Gradativamente, a legislação mais antiga (como alvarás e as Ordenações Filipinas) é substituída na argumentação jurídica de advogados e juízes pelo uso de leis, códigos, decretos e regulamentos elaborados após a Independência. ${ }^{28}$ Entretanto, como mostrou Keila Grinberg ao analisar as ações de liberdade, não desapareceram por completo as imbricações entre o direito costumeiro e as leis positivas: até os anos

25 VELLASCO, Ivan de Andrade. As seduções da ordem: violência, criminalidade e administração da justiça. Minas Gerais, século 19. Bauru, SP: EDUSC, 2004, p.135.

26 Ver, por exemplo, COELHO, Edmundo Campos. As profissões do Império: medicina, engenharia e advocacia no Rio de Janeiro. Rio de Janeiro: Record, 1999, p.159 e ss.

27 O ministro criticou a situação brasileira na qual ainda havia "a anomalia que os tribunais inferiores possam julgar em matéria de direito o contrário do que decidiu o primeiro tribunal do Império". NABUCO, Joaquim. Um estadista do Império. 5 ed. Rio de Janeiro: Topbooks, 1998, v.1, p.257.

28 Para discussão mais aprofundada sobre isto, especialmente no campo do direito civil, ver GRINBERG, Keila. O fiador dos brasileiros: cidadania, escravidão e direito civil no tempo de Antônio Pereira Rebouças. Rio de Janeiro: Civilização Brasileira, 2002. 
1850, os advogados dos escravos ainda usaram dispositivos das Ordenações Filipinas, do direito romano, das leis sobre escravidão indígena para defender os direitos e legitimar as causas dos cativos. ${ }^{29} \mathrm{E}$ institutos muito antigos mantiveram-se presentes, assumindo novas roupagens, como é o caso da ação de arbitragem de que se falará mais adiante.

De origem greco-romana, o instituto da arbitragem estava disposto nas Ordenações Afonsinas (1456), nas Ordenações Manuelinas (1521) e no Título 18 das Ordenações Filipinas (1603). Por meio da carta de lei de 20 de outubro de 1823, esse título passou a vigir no Brasil. No ano seguinte, o instituto da arbitragem foi previsto na Constituição de 1824, cujo artigo 160 fixava: "Nas [causas] cíveis, e nas penais civilmente intentadas, poderão as partes nomear juízes árbitros. Suas sentenças serão executadas sem recurso, se assim convencionarem as mesmas partes". ${ }^{30} \mathrm{~A}$ Resolução de 26 de julho de 1831 estabeleceu o juízo arbitral para o julgamento de causas de seguro. A Lei n. 108 de 11 de novembro de 1837 fez o mesmo para as questões referentes às locações de serviços. O Código Comercial de 1850 previu, no artigo 20, que seriam "necessariamente decididas por árbitros as questões e controvérsias a que o Código Comercial dá esta forma de decisão", a saber: locação mercantil, questões suscitadas entre os sócios durante a existência de sociedade ou companhia, liquidação e partilha de sociedades, salário ou prêmio de pessoas empregadas em navios ou serviço de carga, danos causados por abalroação de navios, impugnação de crédito nas falências. O Código Comercial estabeleceu a arbitragem necessária (obrigatória ou forçada), contrariando o espírito do texto constitucional da época. ${ }^{31}$

Da mesma forma que no Código Comercial, os regulamentos concernentes à mineração propuseram a ação de instituição judicial de arbitragem, revestida de caráter coativo, com árbitros indicados pelas partes e nomeados pelo juiz municipal. Isto foi o disposto no artigo 49 do Regulamento n. 455 de 17 de agosto de 1846, bem como no Decreto 3900 de 21 de junho de 1867. Por conseguinte, o Estado, de fato, afastava o emprego da justiça privada e participava, por meio de funcionários seus, na resolução dos conflitos de interesses surgidos entre os mineradores durante a exploração das lavras, bem como garantia, à força de necessário, a execução da decisão. Assim, nos processos de arbitragem que serão analisados adiante, vê-se que: a) o juiz municipal dirigia todas as fases da ação, inclusive obrigando os litigantes a escolherem os árbitros; b) as pessoas envolvidas eram

29 GRINBERG, Keila. Liberata: a lei da ambiguidade. As ações de liberdade na Corte de Apelação do Rio de Janeiro, século XIX. Rio de Janeiro: Relume-Dumará, 1994.

30 Ver OLIVEIRA FILHO, Cândido de. Curso de prática do processo. Rio de Janeiro: Ed. do autor, 1938, v.1.

31 Ver MOREIRA ALVES, José Carlos. Direito romano. 3 ed. Rio de Janeiro: Forense, 1971, v.1, p.203 e ss. Por causa do choque com o art. 160 da Constituição de 1824, a obrigatoriedade da arbitragem no Código Comercial foi afastada pela Lei no 1350 de 14 de setembro de 1866. Todavia, a prática da ação arbitral não desapareceu. 
citadas por oficial de justiça; c) as audiências entre as partes ocorriam na sede do Juízo Municipal; d) a sentença final era proferida pelo juiz municipal, cotejando os pareces dos árbitros com os diplomas legais em vigor; e) a presença de advogados das partes era praxe em todas as fases do processo, fazendo alegações, solicitando vistas, ações de embargos e mesmo de demolições; f) a Administração Geral dos Terrenos Diamantinos era frequentemente instada a produzir laudos técnicos (vistorias, medições).

Ora, todos estes elementos indicam que se estava, no período em tela, diante de outra manifestação de fenômeno de duração alargada na história jurídica brasileira - o processo de arbitragem - que, se na superfície assume certa imutabilidade de feições, na verdade sofrera alteração no âmbito do novo ambiente criado pelas reformas da Justiça. Na segunda metade do século XIX, os processos de arbitragem na mineração contavam diretamente com controle e participação de juízes, oficiais de justiça e autoridades governamentais, não havendo lugar neles para os juízes de paz. ${ }^{32}$ Por isso, muito provavelmente as partes litigantes viam neles uma prestação jurisdicional do Estado, capaz de receber as demandas de grandes e pequenos mineradores. Sem dúvida, a forma de arbitragem é antiquíssima, mas trata-se aqui de atentar para um traço essencial dela, a combinação de diferenciação com preservação.

Em resumo, os processos de arbitragem na mineração oitocentista de diamantes, que se passará a analisar em seguida, podem ser vistos como parte do que Patricia Ann Aufderheide caracterizou como processo de ampliação da justiça e padronização dos seus procedimentos, que ocorreu por meio das reformas judiciais da primeira metade do século XIX, e resultou na limitação do poder privado e na maior acessibilidade dos homens livres à mediação institucional de seus conflitos. ${ }^{33}$ É, pois, contra esse pano de fundo que se deve compreender a permanência de dispositivos antigos em certos campos do novo quadro jurídico do Império.

\section{A Justiça e a solução dos conflitos entre mineradores}

Enquanto a Administração Geral dos Terrenos Diamantinos cuidava de observar e fiscalizar os trabalhos dos homens que andavam longe, "pelas serras, pelos rios,/ tentando a sorte nas catas", ${ }^{34}$ a que órgão cabia a missão de resolver as contendas surgidas entre mineradores vizinhos, entre amigos que se tornavam inimigos durante a cata ou na hora de dividir o produto da

32 Na documentação cartorária de Diamantina e do Serro (antiga Vila do Príncipe), a pesquisa ainda não localizou ações arbitrais referentes à mineração anteriores à década de 1850. A busca, obviamente, prossegue.

33 AUFDERHEIDE, Patricia Ann. Order and violence: social deviance and social control in Brazil, 1780-1840. Minneapolis: University of Minnesota, 1976 (História, PhD. Dissertation).

34 MEIRELES, Cecília. Romanceiro da Inconfidência, p.44. 
lavra? ${ }^{35}$ O "vasto furacão de desvarios" - desatado por ódios, hipocrisias, cobiças, invejas, traições - engendrava numerosas demandas para as quais deveria existir pelo menos a possibilidade de se encontrar soluções não casuísticas. Quando as normas costumeiras do garimpo falharam, o que aconteceu com frequência, foi a Justiça que entrou no horizonte de faiscadores, garimpeiros e grandes mineradores.

Munidos de procuradores, os homens da mineração não hesitaram: recorreram à Justiça. Os juízes municipais do Serro e de Diamantina receberam as querelas, ouviram as razões das partes e produziram sentenças. A Tabela 1 traz o número de ações arbitrais sobre conflitos em serviços de mineração na antiga Demarcação Diamantina, relativas ao período em estudo.

\section{Tabela 1}

Processos de Arbitramento na mineração

Diamantina, décadas de 1850-1880

\begin{tabular}{c|c}
\hline Décadas & $N^{\circ}$ de ocorrências \\
\hline 1850 & 01 \\
1860 & 04 \\
1870 & 02 \\
1880 & 03 \\
TOTAL & 10 \\
\hline
\end{tabular}

Fonte: Cartórios do $1^{\circ}, 2^{\circ}$ e $3^{\circ}$ Ofícios de Diamantina. BAT.

Os números da tabela, que constituem parte pequena das ações judiciais relacionadas ao garimpo, referem-se apenas às controvérsias sobre as operações nos terrenos de catas regularmente arrendados, refletindo as disputas entre agentes mineradores que atuavam legalmente no interior de sociedades ou em áreas contíguas. ${ }^{36}$ Conforme registros da Fazenda Pública, no período de 1875-1890, havia no município de Diamantina 750 títulos de lotes diamantinos arrendados. Os processos analisados neste artigo envolveram 20 títulos de lotes diamantinos, ou seja, 2,7\% do total de registros de arrendamentos. ${ }^{37} \mathrm{O}$ frenesi provocado pelas grandes descobertas no distrito de São João da Chapada, ao gerar ambiente de maior competição pelas jazidas e fazer crescer as expectativas de ganhos entre

35 Sobre a atuação da Administração Geral dos Terrenos Diamantinos em meados dos Oitocentos, ver MARTINS, Marcos Lobato. A mineração de diamantes e a Administração Geral dos Terrenos Diamantinos: Minas Gerais, décadas de 1830-1870. Anais do XV Seminário sobre a Economia Mineira, Diamantina, CEDEPLAR/UFMG, 2012.

36 A pesquisa ainda não levantou quantos processos criminais (ofensas físicas, ameaças, danos, homicídios, furtos, roubos etc.) envolvendo garimpeiros tiveram origem em disputas não resolvidas do tipo tratado neste artigo, isto é, conflitos decorrentes dos procedimentos usados por garimpeiros e faiscadores na exploração das jazidas.

37 APM. Registro de lotes arrendados e dos arrendatários no município de Diamantina, 1875-1890. FP-107, fls.91-125. 
os mineradores, talvez seja o fator explicativo do maior número de processos de arbitramento registrados na década de 1860. Por sua vez, a década seguinte, dominada pela forte queda internacional dos preços do diamante e, por conseguinte, pela redução do ímpeto minerador regional, figura na tabela com o menor número de casos.

Tome-se para análise, primeiramente, um processo judicial no qual as partes eram grandes mineradores. Este foi o caso do pedido de juízo arbitral relativo à Sociedade do Barro, que explorava uma lavra riquíssima nas cercanias de São João da Chapada. Os sócios eram Felisberto Ferreira Brant, Francisco Gomes Ribeiro, João da Silva Maia, Dr. Antônio Augusto Machado e Dona Maria Antônia Correia Dó (com seu filho e genro). Nos anos de 1855-1856, conforme o livro da sociedade, a relação da lavagem do Barro foi a seguinte: a) total extraído: 71:963\$373rs; b) despesas de 185556: 8:635\$987rs; c) comissão de 5\% do diretor: 3:166\$369rs. No biênio em que operou a sociedade, o lucro líquido alcançou 60:162\$914rs, quantia bastante expressiva. Na liquidação da sociedade, a parte de cada sócio ficou em: a) Francisco Gomes Ribeiro: 10:435\$610rs; b) Felisberto Ferreira Brant: 16:174\$480rs; c) João da Silva Maia: 14:521\$650rs; d) Dona Maria Antônia Dó: 10:725\$200rs e; e) Dr. Antônio Augusto Machado: 8:304\$074rs. ${ }^{38}$

Em 10 de julho de 1856, João da Silva Maia, por seu procurador Dr. Manoel Frederico da Costa Pinto, interpelou ao Sargento-Mor Felisberto Ferreira Brant, nos seguintes termos:

\begin{abstract}
Por parte do seu constituinte João da Silva Maia, trazia e vinha citado o SargentoMor Felisberto Ferreira Brant, para aprovar um dos louvados nomeados Rodrigo de Souza Reis e Antônio Felício dos Santos, e propor por sua parte dois outros para ser um aprovado, a fim de que depois de juramentados os mesmos louvados, procedam em uma liquidação em regra do produto e despesas da Sociedade de Mineração existente entre o autor e o réu e outros sócios, e feita esta liquidação decidirem ou julgarem o que for justo, acerca da dedução feita pelo réu de $5 \%$ do produto da lavra tendo debaixo das pessoas cominadas na petição, e acusar a citação, que ao réu fora feita pelo Oficial de Justiça João Francisco Bolina. E sendo presente na mesma audiência o Dr. Joaquim Felício dos Santos, procurador do réu, (...) por ele foi dito que por parte de seu constituinte o Sargento-Mor Felisberto Ferreira Brant oferecia uma exceção de (?) competência do Juízo Arbitral, requerido pelo autor, e requer que fique assinado ao autor o termo de 5 dias para impugnar. ${ }^{39}$
\end{abstract}

Note-se, de início, o quilate dos homens envolvidos neste processo de juízo arbitral. Os Brant e os Felício dos Santos constituíam duas das mais distintas e prestigiadas famílias locais, donas de fortunas imensas decorrentes dos negócios de mineração, militantes na política mineira. Os

38 BAT. Traslado dos autos entre partes. Cartório do $1^{\circ}$ Ofício, maço 122, 1856, fls.08-12v. 39 BAT. Traslado dos autos entre partes. Cartório do $1^{\circ}$ Ofício, maço 122, 1856, fls.03-03v. 
árbitros sugeridos pelo apelante João da Silva Maia - Rodrigo de Souza Reis e Antônio Felício dos Santos - eram mineradores experimentados, além de negociantes bem sucedidos. Possuíam, portanto, amplo conhecimento das práticas e dos costumes vigentes na mineração regional.

Em segundo lugar, ressalte-se o assunto da arbitragem. A questão girava em torno de costumes que norteavam as relações entre os sócios na exploração de lavras. João da Silva Maia considerou ter sido iludido por Ferreira Brant, uma vez que este último teria subtraído quantia de cerca de nove contos de réis como comissão pelos seus trabalhos de administração da lavra do Barro, no momento da liquidação da sociedade, sem avisar a João Maia. Esta atitude de Ferreira Brant não seria conforme aos costumes locais, razão pela qual João Maia exigia o juízo arbitral. Nos termos do processo, queixava-se Maia: "Ora não sendo costume que os sócios administradores de lavras façam tais deduções, devia o réu declarar que a havia feito, e não calar-se, obtendo a assinatura do autor para melhor concessiar (sic)". ${ }^{40}$

Uma tentativa de conciliação no Juízo de Paz foi feita no mesmo dia 10 de julho de 1856. A Felisberto Ferreira Brant foi proposto restituir a João da Silva Maia a quantia de 9:049\$909rs que ele havia deduzido a seu arbítrio, a pretexto de se fazer pagamento ao sócio gerente e ao assistente das lavagens no serviço do córrego de São João, dedução que fora efetuada no último dividendo no produto das vendas dos diamantes extraídos pela sociedade. ${ }^{41}$

A tentativa de conciliação não prosperou. Felisberto Ferreira Brant, que era o diretor da Sociedade do Barro, alegou que fizera a dedução como remuneração dos serviços por ele prestados como sócio gerente com o título de Diretor, e que a percentagem de 5\% não fora deduzida do total de diamantes extraídos, mas sim do que restara depois de liquidada a sociedade e quitadas as despesas. Brant também afirmou que a comissão teria sido decidida pelos sócios, bem como que João da Silva Maia fora informado. Conforme os autos:

Na liquidação da sociedade, o dividendo e a partilha dos lucros foram apresentados a João Maia, que aprovou sem fazer reclamação alguma assinando como os demais sócios o recibo da importância que lhe coube em pagamento no dividendo que se fez dos lucros deduzidas as despesas (...), o que tudo consta do livro da sociedade. ${ }^{42}$

O procurador de Ferreira Brant, Dr. Joaquim Felício dos Santos, pleiteou ao Juiz Municipal que considerasse o pedido de arbitramento improcedente,

40 BAT. Traslado dos autos entre partes. Cartório do $1^{\circ}$ Ofício, maço 122, 1856, fl.16.

41 BAT. Traslado dos autos entre partes. Cartório do $1^{\circ}$ Ofício, maço 122, 1856, fl.04.

42 BAT. Traslado dos autos entre partes. Cartório do $1^{\circ}$ Ofício, maço 122, 1856, fl.05. 
julgando-se a controvérsia de acordo com o Código Comercial de 1850. Com base no artigo 348 do Código Comercial, o Dr. Felício dos Santos alegava que seu cliente estaria a salvo da reclamação de João da Silva Maia, uma vez que este assinara a liquidação da sociedade e, portanto, deveria cessar qualquer reclamação das partes entre si e, assim, seria incompetente o juízo arbitral requerido pelo apelante. Alegava ainda que João da Silva Maia não fizera a reclamação dentro do prazo de dez dias estipulado pelo Código Comercial, a contar da data da comunicação da liquidação da sociedade, que ocorrera em 25 de março de 1856. ${ }^{43}$ Apesar dessas alegações, o Dr. Felício dos Santos aceitou o nome de Rodrigo de Souza Reis para louvado e apresentou outros nomes para essa função. Em meados de agosto de 1856, o Juiz Municipal decidiu pela intimação de testemunhas. Não se localizou a documentação referente ao final desse processo.

Se a decisão final favoreceu João da Silva Maia ou o Sargento-Mor Felisberto Ferreira Brant pouco importa. O fundamental é o fato de a Justiça ter sido acionada, sendo aceita pelas partes, portanto, como esfera legítima para a resolução de conflitos. E as posições do apelante e do réu indicam também como o avanço da institucionalização, nos quadros da consolidação e modernização do Estado Nacional, produzia atritos inevitáveis entre - Costume e a Lei. João da Silva Maia apoiou sua reclamação nas regras costumeiras do garimpo, enquanto Felisberto Ferreira Brant justificava sua conduta nos princípios subjacentes ao então novíssimo Código Comercial do Império do Brasil. ${ }^{44} \mathrm{Na}$ verdade, o Juiz Municipal viu-se às voltas com um "choque de mentalidades" nas terras altas do Norte de Minas.

No território do distrito de São João da Chapada, região onde se situaram os maiores "descobertos" de meados do século XIX, outra ação arbitral correu envolvendo mineradores de escol, no ano de 1882. Esta ação girava em torno de limites de lotes diamantinos, abrangendo também disputa relativa à construção de canal dentro das áreas de cata. As partes foram o Coronel Isidoro Alves dos Santos Laguna, autor da ação, e Henrique Brasileiro Homem, réu, morador do distrito de São João da Chapada. A ação deu entrada na Justiça de Diamantina em 04 de dezembro de 1882. Na petição inicial pode-se ler:

Diz o Coronel Isidoro Alves dos Santos Laguna, arrendatário do lote de terreno diamantino, constante do título junto, que tendo desaparecido os respectivos marcos do mesmo, deu-se, em consequência disso, questão de limites entre o suplicante e Henrique Brasileiro Homem, arrendatário confinante, pretendendo este minerar no terreno e lote do suplicante, que não desejando senão o que

43 BAT. Traslado dos autos entre partes. Cartório do $1^{\circ}$ Ofício, maço 122, 1856, fl.06.

44 O Código Comercial, Lei n 556 de 25 de junho de 1850, possuía artigos modernizadores referentes à regulamentação dos bancos, organização de companhias de comércio e sociedades anônimas e por comanditas. Ele vinculou a iniciativa privada ao Estado imperial, criando um "patriciado mercantil". Cf. VAINFAS, Ronaldo (org.). Dicionário do Brasil Imperial (1822-1889). Rio de Janeiro: Objetiva, 2002, p.143-145. 
Ihe pertence, e ao mesmo tempo buscando interessar ao arrendatário limítrofe, por ser filho de seu compadre e amigo, hoje finado Luiz Antônio Homem, lançou mão de todos os meios amistosos que foram frustrados pelo suplicado, razão porque recorre ao meio legal para garantir a integridade de seu arrendamento. ${ }^{45}$

Veja-se que o autor do processo primeiro tentou acordo, explorando seu prestígio e sua posição na rede de relações sociais existente no distrito de Chapada: Santos Laguna era "compadre e amigo" do pai da outra parte. Quando percebeu que seu poder, material e simbólico, não fora suficiente para demover o jovem afilhado e tudo resolver no âmbito da lógica privada, inclinou-se a acionar a Justiça. A decisão do Coronel Isidoro Laguna assentava-se nas prescrições do Decreto 3.900, de 21 de junho de 1867, que dispunha sobre o juízo arbitral. Dessa forma, o minerador Henrique Homem foi intimado a juízo e, nele, deveria escolher árbitros que, depois de conhecer a questão, fariam o julgamento de fato e de direito. Da parte do Coronel Isidoro Alves dos Santos Laguna, os árbitros indicados foram Serafim Moreira da Silva e Dr. Catão Gomes Jardim. ${ }^{46}$ Na audiência de 20 de dezembro de 1882, Henrique Brasileiro Homem indicou os nomes de dois árbitros: Dr. Joaquim Felício dos Santos e Capitão João Felício dos Santos. Nessa mesma audiência, os advogados das partes combinaram que: a) os árbitros seriam Dr. Catão Gomes Jardim e Capitão João Felício dos Santos e o terceiro árbitro, se necessário, seria o Dr. Armando Bovet (diretor do serviço de mineração diamantina); b) o prazo para a decisão seria de dois meses. ${ }^{47}$

Novamente, convém insistir na qualidade dos homens indicados e escolhidos para desempenhar o papel de juízes árbitros. Eram homens de fortuna e prestígio, conhecedores do mundo da mineração. As partes se ombreavam na intenção de designar figuras de peso para arbitrar as demandas. Estratégia que nada tinha de ingênua ou gratuita, pois parece que cada parte tentava, assim, angariar alguma vantagem no decorrer das fases do processo, como que transferindo o peso específico do árbitro que ela indicava para as decisões a serem tomadas.

$\mathrm{Na}$ causa arbitral em tela, o Coronel Isidoro Laguna queixou-se também da construção de um canal para lavagem de cascalhos que Henrique Homem havia realizado, porque tal canal passaria dentro de seus terrenos, atrapalhando os serviços em sua lavra. Por isso, o Coronel Laguna avaliou "a presente causa em 10 contos de réis para estabelecer a respectiva alçada, pois, além do imposto que tem pago de um lote há 23 meses, despendeu

\footnotetext{
45 BAT. Ação arbitral. Cartório do $2^{\circ}$ Ofício, maço 257, 1882, fl.01.

46 BAT. Ação arbitral. Cartório do $2^{\circ}$ Ofício, maço 257, 1882, fl.02. Para substitutos dos árbitros, o Coronel Isidoro Laguna indicou os nomes de Antônio Ludmiro de Almeida e Comendador José Ferreira de Andrade Brant, dois poderosos mineradores.

47 BAT. Ação arbitral. Cartório do $2^{\circ}$ Ofício, maço 257, 1822, fl.04v-05.
} 
nas primeiras explorações com o finado Capitão Luiz Antônio Homem, mais de cinco contos de réis". 48

A Administração Geral dos Terrenos Diamantinos foi imediatamente chamada a participar do processo. Inicialmente, coube-lhe fornecer cópias completas dos termos de contratos de arrendamento (e respectivas demarcações) do Coronel Isidoro Laguna e de Henrique Homem. Em seguida, o Prático da repartição foi incumbido de vistoriar a área do litígio, apresentando relatório aos árbitros. Conforme o relatório, o Prático notou que as marcas originais permaneciam visíveis em seus lugares e que os arrendatários não teriam alterado as demarcações dos lotes confinantes. ${ }^{49}$

Nos primeiros meses de 1883, a ação arbitral recebeu pedidos de vista de parte a parte e muitas medições foram feitas nos lotes do contencioso. Os árbitros terminaram opinando que o canal construído por Henrique Brasileiro Homem não invadia os terrenos do Coronel Isidoro Alves dos Santos Laguna. Dessa forma, no dia 14 de abril de 1883, depois de seis meses da abertura da ação, o Juiz Municipal de Diamantina julgou improcedente a reclamação proposta pelo Coronel. O prazo combinado pelos advogados das partes - dois meses para a decisão final - foi extrapolado. Mesmo assim, dada a importância da causa, a Justiça proferiu sentença em tempo bastante razoável.

Se os grandes mineradores recorriam à Justiça, o mesmo faziam os pequenos "cateadores" da antiga Demarcação Diamantina. É hora de examinar os processos de arbitramento movidos por simples garimpeiros, seja contra outros mineradores, seja contra donos de terras. Começa-se pelo lugar denominado Rio das Pedras, nos arredores do Arraial de São Gonçalo, pertencente ao município do Serro. Ali, em 24 de outubro de 1868, o garimpeiro Justino Machado da Silva apelou contra os mineradores Cornélio Gustavo da Cunha Vale e João da Silva Maia.50 Justino Machado da Silva, representado pelo Dr. Pedro Fernando Pereira Corrêa, solicitou abertura de ação arbitral para decidir sobre questão de limites em um terreno diamantino com os confinantes Cornélio Vale e João da Silva Maia, ambos representados pelo Dr. Joaquim Felício dos Santos. A petição inicial, dirigida ao Juiz Municipal Francisco Corrêa Ferreira Rabelo, apresentava o litígio nos seguintes termos:

Diz Justino Machado da Silva que ele é arrendatário de um lote de terrenos diamantinos no lugar denominado Rio das Pedras, confinando como V. S. verá dos títulos juntos com os herdeiros de Antônio do Carmo Vale, e com Santos Moreira da Silva de que é cessionário João da Silva Maia, ficando a outra extremidade do lote também

48 BAT. Ação arbitral. Cartório do $2^{\circ}$ Ofício, maço 257, 1882, fl.02.

49 BAT. Ação arbitral. Cartório do $2^{\circ}$ Ofício, maço 257, 1882, fl.08. O relatório do prático da Administração Geral dos Terrenos Diamantinos é de janeiro de 1883.

50 Trata-se do mesmo João da Silva Maia que apelou contra o Sargento-Mor Ferreira Brant no caso anteriormente analisado da Sociedade do Barro. 
confinando com o lote que foi arrendado por Manuel José de Paula, de quem é ainda cessionário o mesmo João da Silva Maia. Acontecendo que se tenha turbado a divisa do suplicante por ter-se mudado de lugar um marco, que se acha junto a um morrinho de congos, e que dista da linha divisória do lote que foi do mesmo Paula, dando em resultado que o lote de Santos Moreira da Silva venha prejudicar em 40 braças ao suplicante, com grave prejuízo de seus trabalhos adiantados. ${ }^{51}$

Em nome de seus constituintes, o Dr. Joaquim Felício dos Santos alegou que a questão, sendo apenas de divisas, não se lhe aplicaria o artigo 49 do Decreto de 17 de agosto de 1846, relativo à tipificação do juízo arbitral. O advogado pediu que se mandasse o Prático juramentado da Administração dos Terrenos Diamantinos ao lugar para, em vista dos títulos dos seus constituintes, declarar se os marcos se achavam ou não colocados em seus verdadeiros lugares. O Juiz aceitou a argumentação de Felício dos Santos. ${ }^{52}$

Em 27 de dezembro de 1868, o Prático da Administração, Francisco de Paula e Souza Matos, realizou a vistoria nos altos dos Caldeirões e Rio das Pedras, achando conforme os títulos e medições primitivas os marcos, faltando, porém, um deles, mas sem prejuízo das divisas. ${ }^{53}$ Diante do relatório do Prático, o procurador de Justino Machado da Silva insistiu na solicitação do juízo arbitral, uma vez que a lavra de seu constituinte continuava paralisada, justamente nas partes confinantes com os serviços tocados por João da Silva Maia. Decorrido algum tempo, em função de pedido de vista do processo pelo Dr. Felício dos Santos, as partes nomearam e aprovaram árbitros. Nesse interim, o lote diamantino de Justino Machado da Silva sofreu invasão. A querela complicou-se mais.

Os invasores eram Francisco Ribeiro de Souza, sua mulher e outros trabalhadores, que foram autorizados por João da Silva Maia a tocar serviço no lote de que este último era cessionário. Imediatamente, Justino Machado da Silva pediu providências ao Juízo. Em 5 de fevereiro de 1869, o Oficial de Justiça Sebastião Francisco Borba executou auto de embargo do serviço de Francisco Ribeiro de Souza. ${ }^{54}$

Durante três meses, esta ação arbitral correu entre pedidos de vistas, vistorias e novas medições, enquanto prosseguiu a pequena cata rasa com um pequeno paiol de areia tocada por Francisco Ribeiro de Souza, a despeito do embargo existente. O Juiz Francisco Corrêa Rabelo terminou convencido de que as ações de João da Silva Maia prejudicaram os trabaIhos de lavra de Justino Machado da Silva, dando-lhe ganho de causa em 30 de abril de 1869. Além das custas do processo, João da Silva Maia foi obrigado a pagar pequena indenização ao garimpeiro Justino Machado da Silva. Assim, a ação arbitral correu no prazo de seis meses.

51 BAT. Ação arbitral. Cartório do $1^{\circ}$ Ofício, maço 126, 1868, fl.03.

52 BAT. Ação arbitral. Cartório do $1^{\circ}$ Ofício, maço 126, 1868, fl.16.

53 BAT. Ação arbitral. Cartório do $1^{\circ}$ Ofício, maço 126, 1868, fl.16v.

54 BAT. Ação arbitral. Cartório do $1^{\circ}$ Ofício, maço 126, 1868, fl.22. 
Vale destacar duas coisas no processo que envolveu Justino Machado da Silva, Cornélio Gustavo da Cunha Vale e João da Silva Maia. Primeiro: o fato de ser comum o titular de direito minerário ceder a outrem a efetiva exploração do lote de terreno diamantino. João da Silva Maia era quem realmente estava minerando nos lotes de Santos Moreira da Silva e de Manoel José de Paula, no final dos anos 1860. Este tipo de situação trazia complicações para a fiscalização das áreas de lavra, bem como para a imputação de responsabilidades em questões fiscais e ações forenses. Segundo: o emprego de faiscadores, por meio de acertos informais, para promover a exploração irregular de jazidas a mando e em benefício de grandes mineradores. No caso, Francisco Ribeiro de Souza e sua gente realizaram cata - a favor de João da Silva Maia - em lotes que eram objeto de litígio. Os contratadores de diamante do período colonial, especialmente Felisberto Caldeira Brant, serviram-se desse expediente. ${ }^{55}$ No século XX, grandes empresas de mineração também lançaram mão de faiscadores e garimpeiros para minerar áreas nas quais não possuíam direitos minerários ou para se livrarem de passivos ambientais. ${ }^{56}$

No florescente Arraial de Mendanha, que fica estendido nas margens do rio Jequitinhonha ao norte da cidade de Diamantina, em 24 de novembro de 1866 o garimpeiro José Gomes de Oliveira acionou o agricultor Francisco Inácio Fragoso. Segundo os termos dos autos:

Diz José Gomes de Oliveira, mineiro, morador no Arraial de Mendanha, que ele contratou e arrendou um lote de terreno diamantino contendo 4.500 braças quadradas no rio Jequitinhonha, do lado direito do mesmo rio em frente ao arraial, dentro do qual existe uma casa de capim ordinária com um pequeno quintal, que hoje pertence a Francisco Inácio Fragoso por compra que fez a Felipe José da Silva e sua mulher. No lugar em que existe o quintal e que se acha colocada a casa, existem gorgulhos e serviços de grande esperança que o suplicante como arrendatário quer explorar, sendo para isso preciso fazer escavações que inutilizam completamente as plantações e casas. O suplicante, fundado na disposição do artigo 49 do Regulamento n. 455 , de 17 de agosto de 1846, pretende que o suplicado seja indenizado pelo juízo de árbitros. ${ }^{57}$

O apelante propôs para arbitradores os nomes dos Capitães Ezequiel Neto Carneiro Leão e Antônio Miguel de Oliveira Leite, ricos mineradores e chefes políticos do arraial. Requereu ainda que se passasse mandato por bem do qual a outra parte fosse intimada para audiência e apresentasse nomes para louvados. Por meio do advogado Agostinho José Ferreira de

55 FURTADO, Júnia Ferreira O labirinto da fortuna ou os revezes na trajetória de um contratador de diamantes. In: História: Fronteiras. v.ll. Anais do XX Simpósio Nacional da ANPUH. São Paulo: Humanitas/FFLCH-USP, 1999, p.309-319.

56 SCLIAR, Cláudio. Geopolítica das minas do Brasil. Rio de Janeiro: Revan, 1996

57 BAT. Processo de arbitramento. Cartório do $1^{\circ}$ Ofício, maço 122, 1866, fl.02. 
Andrade Júnior, o garimpeiro José Gomes pediu que se fizessem as intimações necessárias e a louvação, bem como lhe fosse dado tempo para levantar a quantia arbitrada para a indenização de Francisco Fragoso. A primeira audiência ocorreu em 24 de novembro de 1866, mas a ela não compareceu o agricultor Francisco Inácio Fragoso.

Dias depois, em 28 de novembro, Francisco Fragoso, por meio do solicitador de causas Francisco Domingos de Oliveira, aceitou os dois árbitros sugeridos pelo apelante. ${ }^{58} \mathrm{Em} 18$ de dezembro, realizados os juramentos dos louvados, procederam-se às avaliações da propriedade citada no Arraial de Mendanha. O Capitão Ezequiel Neto Carneiro Leão avaliou em um conto de réis a propriedade, enquanto o Capitão Antônio Miguel de Oliveira Leite fixou o preço do imóvel em 1:200\$000rs. Por causa das avaliações discrepantes, um terceiro avaliador foi nomeado - Sebastião de Pinho Tavares, minerador, comerciante e político - e este, finalmente, chegou à cifra de 1:200\$000rs pela propriedade. Dessa forma, o juízo arbitral fixou a indenização que José Gomes de Oliveira deveria pagar a Francisco Inácio Fragoso em 1:200\$000rs.

No dia 26 de dezembro de 1866, o garimpeiro José Gomes comunicou a sua desistência ao Juiz Bernardino José Pereira de Queirós, alegando que a quantia indenizatória inviabilizava a exploração do gorgulho existente na propriedade de Francisco Fragoso. O minerador era de opinião que o produto da cata dificilmente superaria a soma da indenização com as despesas do serviço. Então, foi a vez de Francisco Inácio Fragoso bater pé: ele não aceitou a desistência de José Gomes e tentou obrigar o minerador a pagar a quantia de 1:200\$000rs. O advogado de José Gomes apresentou sua réplica. Por fim, a sentença do Juiz, publicada em 22 de janeiro de 1867, não deu ganho de causa ao agricultor Francisco Inácio Fragoso e ainda o obrigou a pagar as custas do processo.

Salta aos olhos a celeridade deste processo, que tramitou em cerca de três meses. Prazo para solução de conflito de interesses que não empatava a vida e as atividades das partes em litígio. E que, sem dúvida, tornava mais razoável a estratégia de recorrer à Justiça. Por outro lado, fica evidente que, mesmo nos locais onde havia ricas jazidas de diamante, a vontade dos mineradores não reinava absoluta. Eles próprios tinham, em alguma medida, a percepção disso. Um simples casebre ou um quintal com lavoura de subsistência, quando assentado sobre cascalho promissor, exigia cautela por parte do arrendatário de terreno diamantino. Para principiar o serviço de lavra, era preciso selar ajustes na Justiça.

58 Solicitador de causas era o indivíduo habilitado por lei para requerer os processos, despachos ou quaisquer negócios forenses de outrem. CAUDAS AULETE, Francisco Júlio. Dicionário contemporâneo da língua portuguesa. 2 ed. brasileira. Rio de Janeiro: Delta, 1968. (1ª edição portuguesa: 1884). 
Como já foi salientado anteriormente, o processo arbitral envolvendo José Gomes e Francisco Fragoso também evidencia o papel destacado que os grandes mineradores, homens de prestígio em suas comunidades, desempenhavam na condição de árbitros. A busca de soluções institucionais para os contenciosos na mineração, dotadas de valor jurídico e com a aura de legitimidade que parecia emanar da esfera estatal, não prescindia da participação dos "grandes" da antiga Demarcação Diamantina. Pode-se pensar que a forma da ação arbitral, mecanismo escolhido por mineradores e garimpeiros para dirimir os conflitos surgidos durante os serviços de lavra, de certa forma acomodava o modelo do "favor" no âmbito de uma Justiça que caminhava para a racionalidade burocrática, a institucionalização dos procedimentos e a afirmação da esfera pública sobre a privada..$^{59} \mathrm{~A}$ ação arbitral garantia voz ao "pequeno", procurava a conciliação das partes e mostrava-se sensível às tradições da mineração, ao mesmo tempo em que reconhecia a opinião de personalidades destacadas nas comunidades, sem abrir mão de procedimentos racionais e aplicáveis a todos. Nesse sentido, o juízo arbitral, quando incidia sobre as questões do mundo do garimpo, não violentava inteiramente elementos estruturais da cultura garimpeira, das simbologias e dos costumes que vigoravam há muitas décadas entre faiscadores, garimpeiros e grandes mineradores.

Outro aspecto que o referido processo traz à baila é o da relação dos homens livres pobres com a Justiça. O agricultor Francisco Inácio Fragoso, pessoa de posses escassas, não apenas compareceu à Justiça para responder à demanda de outrem. Tentou ativamente usá-la em seu favor, obrigando a outra parte a comprar-Ihe por bom dinheiro sua diminuta propriedade, demonstrando possuir algum conhecimento sobre o funcionamento do aparelho judicial. Nisso, o agricultor contou com os préstimos do solicitador de causas Francisco Domingos de Oliveira. Ora, a atuação desses indivíduos - procuradores encartados - contribuiu para ampliar o alcance da assistência judiciária às pessoas pobres, pelo menos no território dos distritos mais dinâmicos e populosos do vasto município de Diamantina. Eis um tema que os historiadores precisam investigar mais a fundo.

Os processos de arbitramento mostram que os agentes da mineração diamantífera, possuidores de diferentes recursos materiais e simbólicos, ao procurarem solução para suas demandas, não hesitaram em recorrer à máquina judiciária, um poder que não seria facilmente manipulável. Portanto, os costumes do garimpo e a "força dos grandes", comumente vistos como recursos únicos e absolutos no universo da mineração tradicional, não operaram "num vazio propiciado pela inexistência dos poderes públicos, mas em face de uma situação permanente de competição e/ou

59 VELLASCO, Ivan de Andrade. As seduções da ordem. 
composição com as instituições nas quais esses poderes se materializavam". Dessa forma, mesmo os garimpeiros e faiscadores pobres, uma vez envolvidos em conflitos por causa de serviços de lavra, puderam tanto recorrer à proteção pessoal por parte de um potentado como à justiça. $\mathrm{Na}$ verdade, "a existência do aparato judiciário Ihes permitia equilibrarem-se entre as possíveis opções na busca de seus interesses". ${ }^{60}$

\section{Considerações finais}

Vistos em conjunto, os processos de arbitramento examinados apontam para algo que mudava, ou melhor, que estava em construção: a entrada da Justiça no repertório de estratégias de ação à disposição dos homens da mineração oitocentista. Aos poucos, faiscadores, garimpeiros e grandes mineradores descobriram a instância forense, recorreram a ela e acataram suas decisões. Aprenderam a lidar com intimações, ações arbitrais, embargos. Respeitar prazos e saber calar a tempo ou desistir. Acostumaram a constituir procuradores e comparecer a audiências. Nas demandas ligadas ao cotidiano dos serviços de lavra, os homens da mineração perceberam que o juízo arbitral era ferramenta útil para eles, oferecendo-Ihes respostas aos seus contenciosos dentro de prazos curtos.

É preciso relativizar, portanto, a imagem que, há tanto tempo, pinta a sociedade mineradora do diamante como rematado exemplo de mundo hobbesiano, irreversivelmente dominado por cruzamentos sociais violentos, pela cobiça sem peias dos indivíduos, pela corrupção desbragada das autoridades. Esta representação de um inferno oitocentista que expelia gemas preciosas nas formações e contrafortes da Serra do Espinhaço, no nordeste de Minas Gerais, promove a naturalização da violência no território da antiga Demarcação Diamantina. Se bem que não se possa negar que tudo isso existiu - e ainda existe - na região, igualmente verdadeira foi a presença e atuação de uma Justiça que se afirmou com certo vigor, gradualmente, alcançando os sertões montanhosos, as zonas de lavra mais distantes das cidades. Uma Justiça vista por muitos como um tanto "encabulada" diante das resistências que encontrava, mas que perseguiu a institucionalização, cujos magistrados e oficiais possuíam em graus diversos uma concepção de Estado e de vida civilizada. Impulso que a tornava capaz de vergar individualidades obstinadas com a força dos princípios basilares da Lei, e assim injetar alguma estabilidade e previsibilidade nos garimpos e faisqueiras. Enfim, uma Justiça que contribuiu para ordenar convivências no espaço social da mineração, marcado por diferenças e hierarquias.

60 VELLASCO, Ivan de Andrade. Clientelismo, ordem privada e Estado no Brasil oitocentista: notas para um debate. In: CARVALHO, José Murilo de; NEVES, Lúcia Maria Bastos Pereira das. (orgs.) Repensando o Brasil do Oitocentos: cidadania, política e liberdade. Rio de Janeiro: Civilização Brasileira, 2009, p.94 e p.95. 